\title{
Função Social da Escola: compreensões e multiplicidades
}

\author{
School Social Function: understandings and multiplicities
}

Gilberto Oliari
Doutorando em Educação pelo PPGE/UFSM.
Mestre em Educação pelo PPGE/UNOCHAPECÓ.
Licenciado em Filosofia e Ciências da Religião pela UNOCHAPECÓ.
Bolsista Pós-Graduação FUMDES/UNIEDU.
Professor da UNOCHAPECÓ e de Escola Pública da Rede Estadual de Santa Catarina.
gilba@unochapeco.edu.br
IDernanda Monteiro Rigue
Foutora em Educação pelo PPGE/UFSM.
Mestra em Educação pelo PPGE/UFSM.
Licenciada em Química pelo Instituto Federal Farroupilha - Campus São Vicente do Sul.
fernanda_rigue@hotmail.com

Raquel Brum Sturza

Doutoranda em Educação pelo PPGE/UFSM.

Mestra em Educação pelo PPGE/UFSM.

Especialista em Gestão Educacional pela UFSM.

Licenciada em Filosofia pela UFSM. Bolsista de demanda Social da CAPES. raquelsturza@hotmail.com

Resumo: O presente artigo tem como objetivo problematizar as compreensões acerca da função social da escola, apresentada por graduados em cursos de licenciatura de diversas regiões do Brasil. Por meio de formulário online, foram coletadas cinquenta e seis respostas que são analisadas e problematizadas, tendo como base sua análise e categorização. O estudo mobiliza-se por meio de um ensaio com inspirações de Larrosa (2003), conjecturando o percurso de investigação a que se propõem os autores. Emerge do estudo, cinco categorias de análise: cidadania; ensino de conteúdo; mão de obra/formação para o mercado de trabalho; formação humana e integral; sem função social (todas com possíveis compreensões da educação como um direito humano). As categorias foram atentamente problematizadas, a partir de autores e pesquisadores que nos servem de inspiração para pensar o campo da educação e/ou escolarização. Desta pesquisa, resultam as mais diversas noções de função social da escola no contemporâneo.

Palavras-chave: Função Social. Escolarização. Ensaio.

Abstract: This paper aims to problematize understandings about the social function of the school, presented by graduates in education degree from different regions of Brazil. By using an online form, fiftysix responses were collected, analyzed and questioned, based on their analysis and categorization. The study is mobilized through an essay (LARROSA, 2003), considering the course of investigation proposed by the authors. In this perspective, five categories of analysis emerge from the study: citizenship; teaching content; labor/ training for the job market; integral human development; without social function (all with possible comprehensions of education as a human right). The categories were carefully problematized, based on authors and researchers who serve as inspiration for thinking about school education. Thus, as a result, are understood the different and diverse notions of the social function of the school in the contemporary.

Keywords: Social function. Schooling. Essay. 


\section{Introdução}

Se pensarmos acerca dos atravessamentos da educação escolar em nossas vidas é saliente a recorrência quanto à presença de uma promessa vinculada à sua função em nossas vivências e também em âmbito social. Função social que se encontra atrelada à noção de escola como apresentação do mundo à crianças e à jovens, visto que, “[...] a criança é introduzida ao mundo pela primeira vez na escola [...] ela é a instituição que interpomos entre o domínio privado do lar e o mundo com o fito de fazer com que seja possível a transição [...] da família para o mundo" (ARENDT, 2007, p. 238). Desse modo, caberia à escola operar como o elo entre a família e o mundo, com a função de apresentar o mundo aos recém-chegados, operando como a fruição de um direito humano.

No entanto, na contemporaneidade, é possível perceber que esta função social da escola, apresentada por Arendt (2007), não é a única possível de ser concebida em se tratando de escolarização. Pode-se perceber que diferentes sujeitos, grupos e também políticas atribuem diferentes funcionalidades e perspectivas a ela. Desse modo, tendo em vista as tramas e demais relações de força que contingenciam nosso pensar acerca do que seria a função social da escola, bem como suas diversas formas de apresentação torna-se emergente o presente estudo.

Problematizar essas nuances que tratam das diferentes compreensões acerca do que seria a função social da escola, tem como pano de fundo chamar atenção para as possíveis e diferentes marcas/atravessamentos dessa instituição nas vidas e nas trajetórias humanas e sociais, desde a infância até a velhice. Afirmamos isso, inspirados no movimento de pesquisa empreendido por Rigue, Oliari, Ribas e Sturza (2020), quando apresentam um conjunto de narrativas as quais descrevem os diferentes efeitos da escolarização em suas vidas. Desse modo, ao pensarmos acerca das noções que abordam a função social da escola, não visamos produzir uma verdade absoluta/naturalizada acerca da mesma, ao contrário, a colocamos em pulverização para problematizar suas marcas e afetações no que tange suas nuances históricas.

O objetivo deste artigo é problematizar a compreensão de diferentes sujeitos com formação em nível superior em alguma licenciatura, acerca da temática: função social da escola. Para tal, realizamos um levantamento de dados por meio de um formulário online, construído a partir da plataforma Google Docs ${ }^{1}$, o qual foi compartilhado por meio de várias redes online de pesquisadores ${ }^{2}$. Esse formulário contava com um conjunto de quinze (15) questões, sendo: treze (13) de múltipla escolha e duas (2) descritivas. 
Para a elaboração do presente estudo, realizamos a análise de um recorte de cinco (5) questões: quatro (4) de mútipla escolha: (Qual a região do país que você leciona?; Qual o nível de ensino leciona?; Qual área de ensino leciona?; Você conhece os princípios orientadores de currículo de sua área de ensino (DCNs, PCNs, OCNs, BNCC, etc.)? e uma (1) descritiva: (Em sua opinião, qual é o papel social da instituição à qual você leciona?). As questões que sistematizamos nesse estudo têm como intuito, demarcar minimamente quem são os sujeitos respondentes e apresentar a multiplicidade de compreensões acerca da função social da escola.

A construção textual seguiu os passos de um ensaio filosófico e educacional. Segundo Larrosa (2003) “[...] o ensaio é, também, sem dúvida, uma figura do caminho de exploração, do caminho que se abre ao tempo em que se caminha" (p. 112). Nele se alinham diferentes argumentos teóricos de pensadores do campo educacional e compreensões realizadas pelos sujeitos que cotidianamente produzem o dia a dia da escola.

Para o ensaísta, a escrita e a leitura não são apenas a sua tarefa, o seu meio de trabalho, mas também o seu problema. O ensaísta problematiza a escrita cada vez que escreve, e problematiza a leitura cada vez que lê, ou melhor, é alguém para quem a leitura e a escrita são, entre outras coisas, lugares de experiência, ou melhor, ainda, é alguém que está aprendendo a escrever cada vez que escreve, e aprendendo a ler cada vez que lê: alguém que ensaia a própria escrita cada vez que escreve e que ensaia as próprias modalidades de leitura cada vez que lê (LARROSA, 2003, p. 108).

Nesse contexto, o peculiar do ensaio é sua figura enquanto um caminho sinuoso, que atenta para os acidentes dos terrenos, suas noções e suas nuances. Assim, buscamos construir a textualidade da pesquisa que se apresenta.

\section{Desenvolvimento}

Tendo como base para a construção do presente estudo as respostas elaboradas pelos participantes da pesquisa, inicialmente apresentamos os principais achados da mesma, seguida por uma breve análise. Durante a realização da análise e categorização dos achados, manteremos sigilo quanto à identidade dos sujeitos respondentes, visto que ao final do questionário, deixamos claro nossa intenção de utilizar as informações para a construção da pesquisa, mantendo sigilo de identificação e resposta. Desta forma, utilizaremos números de um (1) a cinquenta e seis (56), a fim de identificar os sujeitos e suas respectivas respostas.

Na primeira pergunta nos detivemos em identificar qual região do país em que o docente respondente leciona ou reside. Das cinquenta e seis (56) respostas coletadas, verificamos que a 
maioria dos respondentes concentrou-se na região Sul do Brasil, totalizando 58,9\%; seguida pela região Sudeste com 21,4\%; região Nordeste com 12,5 \%; Centro-Oeste com 5,4\% e região Norte com 1,8\%. O número significativo de respondentes na região Sul, provavelmente encontra-se situado no compartilhamento significativo do formulário entre nossos pares, o que pode ter contribuído para que os sujeitos se motivassem para responder o mesmo.

$\mathrm{Na}$ segunda pergunta, identificamos em qual nível de ensino os docentes respondentes atuam como professores. As respostas compiladas demonstram que, a maioria dos docentes atua na Educação Básica (80,4\%). Nível que compreende a Educação Infantil, o Ensino Fundamental e o Ensino Médio, conforme o que aponta a Lei de Diretrizes e Bases da Educação (LDB) nº 9.394 de 1996. Enquanto que 8,9 \% são professores do Ensino Profissional e Técnico e 3,6\% são professores de Ensino Superior. Além disso, uma pequena parcela $(7,1 \%)$ que possuem formação docente, por sua vez, não estão atuando em nenhuma rede de ensino, no momento. É válido ressaltar, que optamos por incluir a opção: não possui vínculo docente no momento, dentre as alternativas a serem assinaladas. Isto ocorreu, pela percepção de que, muitos dos indivíduos que possuem uma graduação em licenciatura, por algum período já estiveram em sala de aula e poderiam contribuir significativamente com a pesquisa, mesmo não possuindo vínculo empregatício, no momento. O que não poderia mostrar-se como um empecilho para dividirem suas compreensões acerca do papel social da escola na pesquisa.

$\mathrm{Na}$ pergunta que se direcionou à área de conhecimento dos docentes, foi-nos possível identificar que: 33,9\% são oriundos da área de Ciências Humanas e Sociais Aplicadas; 10,7\% da área da Matemática e suas Tecnologias; 19,6\% da área de Ciências da Natureza e suas Tecnologias; 35,7\% da área de Linguagens e suas Tecnologias. Na questão seguinte, indagamos: 'Você conhece os princípios orientadores de currículo de sua área de ensino?', a maioria dos respondentes apontou que $\operatorname{sim}(91,1 \%)$ e os $8,9 \%$ que não possuíam conhecimentos sobre as orientações curriculares de sua área de ensino.

A partir desse levantamento inicial, foi-nos possível realizarmos um apanhado das principais características dos sujeitos envolvidos na pesquisa. O que corrobora para que seja possível apresentar a seguir, o percurso de categorização e análise dos dados resultantes da mesma.

\section{Categorização e análise dos dados}

No questionário, havia uma questão descritiva, na qual os respondentes precisavam dissertar a partir da seguinte questão: "Em sua opinião, qual é o papel social da instituição a qual você leciona?” Essa era uma questão tão indispensável quanto às outras, mas esta em especial, 
exigia do sujeito à redação de uma resposta. Desta forma, a partir dos escritos dos informantes, desenvolvemos uma categorização das respostas, as quais constam abaixo.

Inicialmente, os pesquisadores leram as respostas coletadas por meio do formulário, sem categorias prévias; a intenção era problematizar categorias a partir do que os sujeitos da pesquisa haviam apontado. Após a leitura minuciosa, foi possível elencar cinco (5) categorias, a saber: cidadania, elencando as respostas que apresentavam elementos da sociedade (totalizando dezenove (19) respostas); ensino de conteúdo, abrangendo as compreensões de que a escola deve ensinar aquilo que foi produzido historicamente pela humanidade (totalizando oito (8) respostas); mão de obra/formação para o mercado de trabalho, apresentando as respostas que apontavam para a formação técnica e/ou profissional (totalizando sete (7) respostas); formação humana e integral, abrangendo as respostas elencadas sobre o desenvolvimento integral da pessoa como ser humano (totalizando dezesseis (16) respostas); Sem função social, abrangendo uma (1) resposta que não localiza função social relacionada à escola.

Para além destas, vale destacar que houve dois (2) sujeitos que não responderam com conceitos ou argumentos a questão colocando apenas um ponto final (assim o formulário compreendia que a pergunta estava respondida e permitia a sua finalização). E, outros três (3) que escreveram termos aleatórios, que foram: família e escola, ensino público e BNCC; estes não vêm ao encontro da pergunta presente no questionário, o que nos levou a crer que não contribui para nenhuma das categorias de análise.

Na primeira categoria denominada 'cidadania', a função social da escola mais recorrente foi formar/preparar cidadãos (emergiu aproximadamente dez (10) vezes). Além dessa concepção de função, apareceram: integrar família, escola e comunidade; despertar para responsabilidade social; pensar o mundo para transformá-lo; promover a emancipação; propor soluções dos problemas sociais; etc. Em seguida, apresentaremos alguns excertos que ilustram a sistematização que realizamos:

Acredito que o papel principal seja propiciar aos alunos um ambiente de aprendizagem que faça com que ele se sinta responsável pela sociedade em que está inserido. (R 18)

Torna o aluno crítico, que saiba pensar o mundo a partir da sua realidade para assim transformá-la. Formar um cidadão com preocupação com todas as causas na esfera social. (R 22)

Trabalho numa região em que as famílias são, em sua grande maioria, de baixa renda e vulnerabilidade social, então a escola, deveria estar a serviço de mudança da realidade, preparando-os para uma busca constante de soluções para os problemas encontrados no dia a dia. (R 45)

A escola precisa repensar sobre que tipo de sociedade pretende construir, visto que, seu papel é fundamental na formação do caráter social dos indivíduos. ( $R$ 48) 
Para pensar acerca da incidência do que se produz na escola e na sociedade, é preciso antes de tudo, reconhecer que a sociedade é complexa (em todos os seus campos de organização) e faz parte do mundo social, econômico e político disposto e minimamente organizado. Muito embora exista a possibilidade, pelo menos em termos de narrativa de, fiscalizar, questionar e se posicionar contrário ao que é encaminhado no mundo, tensionamos que uma das noções do que possa ser o papel da escola, esteja vinculado ao de colocar as matérias sociais sobre a mesa e estudá-las para entender suas possíveis relações (MASSCHELEIN; SIMONS, 2017). Talvez, disponibilizando o estudo sobre a sociedade se possa pensar em um processo de constituição dos sujeitos. No entanto, é preciso reconhecer que esse fim (a formação) é da ordem do incerto e do imprevisível.

Não desconsideramos por completo as necessidades de pensar a sociedade e, talvez até de transformá-la por meio da educação. No entanto, torna-se relevante problematizar essas considerações levando em conta o que adverte Arendt (2007), após ter refletido sobre a crise educacional dos Estados Unidos da América em meados da década de mil novecentos e setenta (1970):

O papel desempenhado pela educação em todas as utopias políticas, a partir dos tempos antigos, mostra o quanto parece natural iniciar um novo mundo com aqueles que são por nascimento e por natureza novos. [...] Por esse motivo na Europa, a crença de que se deve começar das crianças se se quer produzir novas condições permaneceu sendo principalmente o monopólio dos movimentos revolucionários de feitio tirânico que, ao chegarem ao poder, subtraem as crianças a seus pais e simplesmente as doutrinam. A educação não pode desempenhar papel nenhum na política, pois na política lidamos com aqueles que já estão educados (ARENDT, 2007, p. 225).

Podemos até contestar a análise e os apontamentos realizados por Hannah Arendt (2007), contudo precisamos reconhecer aquilo que afirmamos acima - os destinos macros da sociedade não estão nas mãos da escola, pelo contrário, quem estabelece os rumos sociais são as múltiplas relações de forças que se tramam em todos os setores e instâncias sociais. Talvez, antes de transformar a sociedade, a escola precise transformar os conteúdos desenvolvidos em sala de aula; o modo como os diferentes conteúdos sociais são estudados; o modo como as mudanças sociais são percebidas; o modo como os rumos macro impactam de modo micro na vida de cada sujeito.

Além da compreensão de Arendt (2007), é indispensável pensarmos acerca da noção de ‘cidadania’ e ‘cidadão’ sob a perspectiva que escreve Nascimento (2007). Para ele: 
O "cidadão" sob vibração da democracia é aquele que 'participa' de maneira entusiasmada, implementando e aprimorando, em seu cotidiano mediato e imediato, dinamismos voltados para o alargamento, aprofundamento e intensificação de seu próprio assujeitamento (NASCIMENTO, 2007, p. 158).

Nesse ponto de vista, é possível visualizar que situar (ou situar-se) na figura de cidadão ${ }^{3}$, tendo em vista sistemas democráticos, encontra-se vinculado a uma estratégia de condução de condutas e, ao mesmo tempo, de formação de sujeitos dóceis e possíveis por meio da escola, assim como as demais instituições que compõem a hierarquia social. Escola como instituição reguladora que compõe com esse movimento de formação dos cidadãos. Nessa perspectiva, a escola aparece como parte de uma engrenagem, que retroalimenta sistemas de subjetivação e condução de condutas.

Em se tratando dos possíveis impactos causados na vida dos sujeitos escolares, adentramos na segunda categoria que emergiu das descrições: o ensino de conteúdos. Nessa categoria, emergiram conceitos e argumentos dirigidos basicamente à tarefa de ensinar, tais como: transmitir conhecimentos, propor reflexões, buscar a verdade, ensinar e preocupar-se com a qualidade do processo de ensino e aprendizagem. Relacionamos abaixo alguns excertos:

Dar informações, ensinar o melhor caminho nas ações diárias, proporcionar conhecimento nas diferentes áreas de ensino. (R 13)

Mostrar para os estudantes os conhecimentos produzidos pela humanidade. $(\mathrm{R}$ 37)

Garantir padrão mínimo de qualidade no processo ensino aprendizagem. (R 52)

Diante dessas compreensões, problematizamos dois posicionamentos: a escola como um espaço de apresentação do mundo aos jovens; e, da formação (ou preparo) do professor para esse ofício. Primeiro, consideramos que é preciso estar atento à noção que Masschelein e Simons (2017) produzem: “[...] a escola é, igualmente, o lugar onde os jovens (de acordo com um método específico) são abastecidos com tudo o que eles devem aprender para encontrar o seu lugar na sociedade" (p. 25), ou seja, segundo os autores, cabe à escola apresentar o mundo as crianças e jovens, para que eles o conheçam e possam inserir-se nele.

Por isso, é que a transmissão de conteúdos pode ser importante, pois afinal, "[....] na escola sempre há alguma coisa sobre a mesa” (MASSCHELEIN; SIMONS, 2017, p. 41, grifos dos autores), esse algo sobre a mesa é transformado em matéria de estudo. Pode não ser algo novo no mundo, algo fantasticamente surgido sobre a mesa naquele instante, possivelmente alguém já viu aquele algo em algum lugar e já pode ter construído um conhecimento sobre ele e, isso que outro já produziu precisa ser transmitido àquele que tem contato a primeira vez. Com essa perspectiva é possível avançar os conhecimentos, partindo daquilo que já foi produzido, avançar para outras interpretações e relações possíveis. 
Em segundo lugar, ainda sobre a transmissão de conhecimentos, é preciso estar atento à advertência que nos faz Arendt (2007) “[....] a qualificação do professor consiste em conhecer o mundo e ser capaz de instruir os outros acerca deste" (p. 239). Com essa noção é preciso estar atento à formação do professor, para que o mesmo ao chegar na escola, esteja atento ao que é, também, de sua responsabilidade, ensinar como o mundo funciona.

Ao mesmo tempo em que as concepções de Masschelein e Simons (2017) e Arendt (2007) são construídas, é importante pontuar a noção que Corrêa (2006) produz. Para ele:

Embora haja muitos tipos de escola, e com as mais variadas e até antagônicas
finalidades, há, entre todas elas, um laço muito forte e que as faz atuantes em um
processo que chamo de escolarização. A obediência a uma lei de alcance nacional
regula desde a frequência de todos os jovens futuros cidadãos à escola, passando
pela seleção dos conteúdos adequados, até a formação do verdadeiro exército
docente responsável pela manutenção das características do ensino que
interessam ao programa de governo do Estado - o laço fundamental do
processo de escolarização (CORRÊA, 2006, p. 23).

O que o autor constitui com essa compreensão passa pela noção de que "[...] cabe ao professor na transmissão dos conhecimentos que desde sua formação profissional sabe que devem ser transmitidos, enquanto aos alunos cabe o papel de receptores dos conteúdos emitidos pelo professor" (p. 27). Aí, podemos pensar nessa categoria (ensino de conteúdos) como uma operacionalização totalizadora escolar do que é naturalizado como 'indispensável' para “[...] todos e cada um” (RIGUE, 2017, p. 119). Como diria Corrêa (2006) “À máquina é confiado o papel de transmitir conteúdos, registrar o progresso da instrução e de controlar o sistema do ensino: tanto mais eficaz quanto mais individual e controlado" (p. 135).

Considerando as diferentes perspectivas de pensar a categoria supracitada, consideramos a terceira categoria elencada 'formação técnica e/ou profissional'. Do conjunto de considerações que emergiram desta categoria, podemos apontar algumas ideias: a função social da escola como instituição responsável por preparar para o mercado de trabalho neste caso, formar mão de obra; transformar o aluno em agente de instrumentalização; etc. Na sequência, apresentamos alguns excertos que ilustram esse pensamento:

Levar a oportunidade de melhor colocação profissional e até mesmo melhora na qualidade de vida de jovens e adultos que por diversos motivos não concluíram a educação básica. (R 12)

Voltado para educação da indústria. (R 30)

Oportunizar diálogos e formação de profissionais técnicos para diferentes áreas. (R 54) 
Consideramos importante problematizar essa categoria de respostas a partir do que Biesta (2013) aponta como uma transação econômica na educação. Essa problematização proposta pelo autor considera três prerrogativas: na primeira, o aprendente torna-se um potencial consumidor, “[...] aquele que tem certas necessidades [...]" (BIESTA, 2013, p. 37) que precisam ser supridas necessidades estas que podem ser externas ao interesse pessoal (subjetivo) dos sujeitos e estar atrelada ao sistema econômico e industrial. A segunda prerrogativa refere-se a possível compreensão de “[...] o professor, o educador ou a instituição educacional são vistos como o provedor, isto é, aquele que existe para satisfazer as necessidades do aprendente [...]" (BIESTA, 2013, p. 37), desse modo, a função social de preparar para o mercado de trabalho estaria muito mais a serviço dos estudantes e do seu interesse, do que dos conhecimentos escolares propriamente ditos. A terceira prerrogativa considera que "[...] a própria educação se torna uma mercadoria uma coisa - a ser fornecida ou entregue pelo professor ou pela instituição educacional, a ser consumida pelo aprendente" (BIESTA, 2013, p. 38). Desse modo, se alinhada à formação de mão de obra, a escola deveria pautar-se pelo princípio da flexibilidade (para atender às necessidades dinâmicas do mundo industrial) e da prestação de contas (afinal, se o aprendente adquiriu algo com a função de aplicá-la na profissão, a escola deve prestar conta disso).

Além da compreensão de Biesta (2013), o que escreve a pesquisadora Marrach (1996) viabiliza pensarmos que a educação escolar está vinculada a uma formação técnica e/ou profissional a qual pode estar relacionada com as forças e os interesses do neoliberalismo. Conforme, a autora:

Assegura que mundo empresarial tem interesse na educação porque deseja uma força de trabalho qualificada, apta para a competição no mercado nacional e internacional. Fala em nova vocacionalização, isto é, numa profissionalização situada no interior de uma formação geral, na qual a aquisição de técnica e linguagens de informática e conhecimento, de matemática e ciência adquirem relevância. Valoriza as técnicas de organização, o raciocínio de dimensão estratégica e a capacidade de trabalho cooperativo (MARRACH, 1996, p. 04).

Compreensão que corrobora com a afirmação que "[....] A integração da universidade à produção industrial baseada na ciência e na técnica, transforma a ciência em capital técnicocientífico" (MARRACH, 1996, p. 04), aí "É como consumidores que o neoliberalismo vê alunos e pais de alunos" (MARRACH, 1996, p. 05). Nesse ponto de vista a escola aparece como esse 'meio' pelo qual os interesses neoliberais das grandes corporações e organizações constituem sua mão de obra 'qualificada' para o mercado nacional e internacional. 
Dentro da categoria de 'formação humana e integral', foi recorrente a presença de conceitos como: orientação de condutas; educação para a vida; desenvolvimento de habilidades para o trabalho e para a convivência social de modo dual e equitativo; tornar os educandos seres pensantes; etc. Dentre esses, o conceito que mais aparece é o conceito de formação, conforme podemos perceber nos excertos a seguir:

Formar seres humanos que consigam colocar-se no lugar do outro e assim serem inseridos no mercado de trabalho com pessoas humanas e justas. (R 9).

Contribuir na formação de sujeitos críticos, autônomos e humanos. (R 20).

Promover domínio de habilidades básicas para inserção no mercado de trabalho e formação da cidadania para a vivência em sociedade. (R 39).

Podemos considerar, a partir das respostas apresentadas acima, uma aproximação com o conceito de formação proposto por Masschelein e Simons (2017), os quais afirmam que:

[...] a formação tem a ver com a orientação dos alunos para o mundo como ele é construído para existir no sujeito ou na matéria, e essa orientação diz respeito, principalmente, à atenção e ao interesse para com o mundo e, igualmente, à atenção e ao interesse para com a própria pessoa em relação ao mundo (p. 48).

Nesse sentido, a formação humana e integral, estaria relacionada, conforme Masschelein e Simons (2017) a um jogo constante no qual o aluno é chamado a sair de si e "[...] ir além do seu próprio mundo da vida por meio da prática e do estudo" (MASSCHELEIN; SIMONS, 2017, p. 49). No entanto, essa prática de formação só é possível em uma escola que busca abrir o mundo para os alunos. Isso significa dizer que os conteúdos escolares são tornados parte do mundo e informam o mundo. Em outras palavras “[...] forma parte do mundo (que podemos, então, compartilhar) e informa, isto é, partilha algo com o mundo existente (e, dessa forma, acrescenta algo ao mundo e o amplia)" (MASSCHELEIN; SIMONS, 2017, p. 49, grifos do autor).

A formação, nesses termos, estaria voltada à ação pedagógica de desafiar os alunos a tomar "[...] parte do mundo em que/pelo qual estamos imediatamente envolvidos, interessados, curiosos, e assim também algo que se torna um inter-esse (algo que não é nossa propriedade mas que é compartilhado entre nós)" (MASSCHELEIN; SIMONS, 2017, p. 50, grifos do autor).

Ao passo que, essa mesma noção de formação humana e integral pode ser pensada a partir do que escrevem Malavolta, Rigue \& Biazus (2020):

"Você precisa ir à escola para não ficar burro", "Você precisa estudar para ser alguém na vida". A educação e sua velha promessa e prospecção de um futuro e mundo melhor. Essas são narrativas que frequentemente crianças e adolescente escutam de seus pais, professores, familiares e amigos (p. 94). 
Formação escolar que aparece relacionada a "Frases carregadas de expectativas, promessas, imposições que, naturalizadas, acabam, muitas vezes, contribuindo para a retirada do sujeito da cena escolar” (MALAVOLTA; RIGUE; BIAZUS, 2020, p. 94). O que corrobora com a seguinte consideração:

[...] podemos pensar que antes do sujeito entrar na escola ele ocupa, perante a sociedade escolarizada, a posição de 'não saber', tendo em vista que precisa habitar o espaço institucionalizado de educação para que esteja 'habilitado' educacionalmente. É nessa contingência que se justifica a entrada do mesmo na escola, para 'ser alguém', para sair do 'não saber'. Nesse sentido, na maioria dos casos a escola é tomada como a detentora do saber, do conhecimento, das noções de verdade sobre a realidade e, o aluno, por sua vez, leva à escola o seu corporeceptáculo, aquele que espera explicações e que sentado em fileiras passa a acreditar ser possível adquirir capacidades/habilidades que $\mathrm{O}$ dignifiquem/qualifiquem como 'cidadão' perante a sociedade (MALAVOLTA; RIGUE; BIAZUS, 2020, p. 95).

Logo, o tensionamento que as autoras apontam, é uma forma de pensar o campo de formação a que a escola está vinculada. Perspectiva que põe em pulverização seus sentidos e significados que reverberam no campo social - de formação humana.

Na última categoria 'Sem função social', nos debruçamos nos escritos de Nascimento (2007) e Marrach (1996) para mencionar sua concepção. Atentando primeiramente ao que escreve Marrach (1996) toma relevo a seguinte problematização:

No Brasil, a modernização neoliberal assim como as anteriores não toca na estrutura piramidal da sociedade. Apenas amplia sua verticalidade, que se nota pelo aumento do número de desempregados, de moradores de rua, de mendigos etc, Em outras palavras, a pirâmide social se mantém e as desigualdades sociais crescem. Para a educação, o discurso neoliberal parece propor um tecnicismo reformado. Os problemas sociais, econômicos, políticos e culturais da educação se convertem em problemas administrativos, técnicos, de reengenharia. A escola ideal deve ter gestão eficiente para competir no mercado. $\mathrm{O}$ aluno se transforma em consumidor do ensino, e o professor em funcionário treinado e competente para preparar seus alunos para o mercado de trabalho e para fazer pesquisas práticas e utilitárias a curto prazo (p. 10).

Nessa perspectiva neoliberal, alia-se um discurso de 'qualidade' o qual, aparece reduzir "[....] os problemas sociais a questões administrativas, esvaziando os campos: social e político do debate educacional, transformando os problemas da educação em problemas de mercado e de técnicas de gerenciamento" (MARRACH, 1996, p. 08). Seguindo a mesma linha, Nascimento (2007) argumenta que:

A vida social deve ser mantida tendo como base o desempenho pessoal atrelado às relativas funções. É desta maneira que permanece existindo as desigualdades intelectual, social, econômica e política. Ser igual perante a lei significa apenas a continuidade das relações assimétricas e hierarquizadas estendidas a todos e que 
a lei tratará cada qual no seu devido lugar. Ao trabalhador cabe, do mesmo modo que ao patronato e aos demais segmentos da classe dirigente, 'igualmente' direitos e deveres (NASCIMENTO, 2007, p. 160).

Com isso, podemos visualizar que as compreensões de Marrach (1996) e Nascimento (2007) corroboram para que pensemos a noção emergente do sujeito que respondeu o questionário "Instituição como coprodutora das problemáticas sociais" (R 7). Noção que vem ao encontro de uma escolarização enquanto continuidade e, porque não, intensificação, das situações e hierarquias no ambiente social.

\section{Considerações finais}

O presente estudo problematizou a compreensão de diferentes sujeitos licenciados nas mais distintas áreas da educação acerca da temática: função social da escola, por meio de um questionário encaminhado na plataforma do Google Docs. Deste, obtivemos cinquenta e seis (56) respostas que nos serviram de referências para construção de categorias de análise.

$\mathrm{Na}$ categorização emergiram 5 (cinco) categorias que abordam a função social da escola (cidadania; ensino de conteúdo; mão de obra/formação para o mercado de trabalho; formação humana e integral; sem função social). Cada uma das categorias foi tensionada e problematizada a partir de perspectivas de autores e pesquisadores que nos servem de inspiração no campo da educação e escolarização.

Resulta dessa pesquisa e deste empenho investigativo a consideração de que, diferentes e diversas são as noções acerca do que seja a função social da escola. Mesmo diante de um público de respondentes que são professores, verificamos uma narrativa multiforme acerca do que seja (possa ser) a função social da escola.

Destacamos que do total das cinquenta e seis (56) respostas dissertativas, a maioria esteve atrelada a categoria 'cidadania' (19), seguida pela categoria 'formação humana e integral' (16). A categoria com menor número de respondentes foi a 'sem função social' (1), a qual, a nosso ver, problematiza significativamente o campo que operacionaliza a educação escolar, por um viés epistemológico de caráter pós-estruturalista.

Autores como Arendt (2007; 2014), Corrêa (2006), Nascimento (2007), Marrach (1996) e Masschelein e Simons (2017), foram referências teóricas que, embora com diferentes perspectivas epistêmicas de pensar o campo da educação e escolarização, contribuíram para que fosse possível construir uma problematização e compreensão ampla das noções de função social da escola, a partir das respostas elaboradas pelos participantes da pesquisa. 
Pontuamos a urgência de unir esforços para pensar e, ao mesmo tempo, problematizar os sentidos e significados que estão sendo permanentemente dados ao que seja a função social da escola. Delimitações que, a nosso ver, ditam e estabelecem modos de perceber e de estar na escola, que, na maioria dos casos, podem vir a ser contingenciados por relações de forças externas e desconexas ao campo pedagógico, como é o caso da política e da economia.

\footnotetext{
${ }^{1}$ As ferramentas do Google Docs funcionam de forma síncrona e assíncrona, portanto, on-line para acessar dados em nuvens e offline através de aplicativos de extensão instalados diretamente do googlee, onde há bancos de dados criados por essa extensão. E permite aos usuários criar e editar documentos online ao mesmo tempo colaborando em tempo real com outros usuários. (COSTA, 2015)

2 Distribuição do link por grupos de Whatsapp e grupos da plataforma do facebook.

3 "Sob estas condições, os integrantes das sociedades modernas são designados pela palavra "cidadão" em substituição ao antigo termo "súdito" ou "vassalo"”" (NASCIMENTO, 2007, p. 159).
}

\section{Referências}

ARENDT, Hannah. Entre Passado e Futuro. São Paulo: Perspectiva, 2007.

ARENDT, Hannah. A vida do espírito: o pensar, o querer, o julgar. Tradução César Augusto R. De Almeida; Antônio Abranches; Helena Franco Martins. Rio de Janeiro: Civilização Brasileira, 2014.

BIESTA, Gert. Para além da aprendizagem: educação democrática para um futuro humano. Belo Horizonte: Autêntica Editora, 2013.

CORRÊA, Guilherme. Educação, comunicação, anarquia: procedências da sociedade de controle no Brasil. São Paulo: Cortez, 2006.

COSTA, Marvim. Google Docs: crie, edite e visualize documentos online. 2015. Disponível em: https://www.techtudo.com.br/tudo-sobre/google-docs-

app.html\#: :text $=\mathrm{O} \% 20 \mathrm{Google} \% 20 \mathrm{Docs} \% 20 \% \mathrm{C} 3 \% \mathrm{~A} 9 \% 20 \mathrm{um}$, quanto $\% 20 \mathrm{na} \% 20 \mathrm{mem} \% \mathrm{C} 3 \%$ B3ria $\% 20$ do $\% 20$ dispositivo Acesso em: 22/03/2020.

LARROSA, Jorge. O ensaio e a escrita acadêmica. Educação e realidade. Porto Alegre, v. 28, n. 2, jul/dez, 2003, p. 101 - 115. Disponível em:

https://seer.ufrgs.br/educacaoerealidade/article/viewFile/25643/14981 Acesso em:

$23 / 07 / 2020$.

MALAVOLTA, Ana Paula Parise; RIGUE, Fernanda Monteiro; BIAZUS, Camila Baldicera. Em Defesa de um corpo-potência: notas sobre educação e política. Revista Interinstitucional Artes de Educar. Rio de Janeiro, v. 6, n.1, pág. 92-118, janeiro-abril, 2020. Disponível em: https://www.e-publicacoes.uerj.br/index.php/riae/article/view/45318 Acesso em: 23/07/2020. 
MARRACH, Sônia Alem. Neoliberalismo e Educação. In: GHIRALDELLI, Paulo (org.). Infância, Educação e Neoliberalismo. São Paulo: Cortez Editora, p. 42-56, 1996.

MASSCHELEIN, Jan.; SIMONS, Maarten. Em defesa da escola: uma questão pública. 2. ed. Belo Horizonte, Autêntica, 2017.

NASCIMENTO, Rogério. Sofisma é imprescindível à democracia ou como mentir apenas dizendo verdades ou ainda "sorria! você está sendo filmado!". Verve - Revista Semestral Autogestionária do NU-SOL. n. 11, p. 156-167, 2007. Disponível em: https://revistas.pucsp.br/verve/article/view/5078, Acesso em: 23/07/2020

RIGUE, Fernanda Monteiro. Uma Genealogia do Ensino de Química no Brasil. 2017. Dissertação (Mestrado em Educação). Universidade Federal de Santa Maria, Santa Maria, 2017. Disponível em: https://repositorio.ufsm.br/handle/1/13153 Acesso em: 23/07/2020.

RIGUE, Fernanda Monteiro; OLIARI, Gilberto; RIBAS, Jéssica Erd; STURZA, Raquel Brum. Vidas em Movimento: Narrativas como estratégia para pensar a escola e trajetórias escolares. In: OLIARI, Gilberto. Artesania do fazer pedagógico: em defesa do escolar. Veranópolis: Diálogo Freiriano, 2020.

Recebido em: 29 mar. 2020/ Aprovado em: 06 jul. 2020

\section{Cite como}

(ABNT NBR 6023:2018)

OLIARI, Gilberto; RIGUE, Fernanda Monteiro; STURZA, Raquel Brum. Função Social da Escola: compreensões e multiplicidades. Dialogia, São Paulo, n. 35, p. 79-92, maio/ago. 2020. Disponível em: https://doi.org/10.5585/dialogia.n35.16907.

\section{American Psychological Association (APA)}

Oliari, G., Rigue, F. M., \& Sturza, R. B. (2020, maio/ago.). Função Social da Escola: compreensões e multiplicidades. Dialogia, São Paulo, 35, p. 79-92. https://doi.org/10.5585/dialogia.n35.16907. 